\title{
Recent Scenario of Impact of Xenobiotics on Marine Fish: An Overview
}

\author{
Jagadeep Chandra S', Chandana GL ${ }^{2}$, Naganagouda V Kote ${ }^{3}$, Sharath Chandra SP ${ }^{4, *}$
}

\section{Jagadeep Chandra S', Chandana $\mathrm{GL}^{2}$, Naganagouda V Kote ${ }^{3}$, Sharath Chandra SP4,*}

'Department of Microbiology, Faculty of Life Sciences, JSS Academy of higher education and research, Mysuru, INDIA.

${ }^{2}$ Department of Biochemistry, Hassan Institute of Medical Sciences, Hassan, INDIA. ${ }^{3}$ Department of Biochemistry, Maharani's Science College for Women, Bengaluru, INDIA.

${ }^{4}$ Department of Biochemistry, Government Science College, Hassan, INDIA.

\section{Correspondence}

\section{Sharath Chandra SP}

Department of Biochemistry, Government Science College, Hassan, Karnataka, INDIA.

Phone no: +91 9902354387;

E-mail: sharathchandrasp@gmail.com History

- Submission Date: 01-08-2020;

- Review completed: 15-09-2020;

- Accepted Date: 22-09-2020

DOI : 10.5530/pj.2020.12.242

Article Available online

http://www.phcogj.com/v12/i6s

Copyright

(C) 2020 Phcogj.Com. This is an openaccess article distributed under the term of the Creative Commons Attribution 4.0 International license.

\section{ABSTRACT}

Xenobiotics from chemicals to plastics have seriously interfered with the biological process of living system. Their impact on aquatic ecosystem, fish in precise is studied with significant interest. However, studies on impact of xenobiotics on marine fish are limited. This literature review integrates and summarizes the impact of xenobiotics on marine fish. The review tries to understand the impact of macro and micro litters, microplastic, metals like mercury and nanoparticles. Finally, we conclude with the ways to regulate the presence and distribution of these xenobiotics in marine environment.

Key words: Fish; Litters; Marine; Xenobiotics.

\section{INTRODUCTION}

Xenobiotics or foreign bodies are difficult to contain given their ubiquity all over the world. ${ }^{1}$ Numerous xenobiotics include chemicals like herbicides, pesticides, metals and their derivatives, pharmaceuticals including antibiotics and many more. Both short and long period exposure to these xenobiotics can cause irreversible damage to living being, with several reports supporting the claim $^{2,3}$. Xenobiotics enter the living system and undertake four stages: absorption, distribution, metabolism and elimination ${ }^{4}$. Standard xenobiotic metabolism follows continuous biotransformation like oxidation, reduction/hydrolysis of the main molecule to produce reactive groups $\left(-\mathrm{NH}_{2},-\mathrm{COOH}-\mathrm{OH}\right)$ followed by conjugation of hydrophilic molecules (glutathione, sulfate, glucuronic acid) to raise the hydrophilicity of xenobiotics culminating in intestinal excretion ${ }^{5}$.

There are also findings where xenobiotics induce carcinogenesis by gene mutation ${ }^{6}$. The effect of xenobiotic pollution in aquatic ecosystem is well documented $^{7}$ and pattern of their impact on fish/ aquatic animals falls under three major categories behavioral, neurophysiological and reproductive ${ }^{8}$. The above effects are usually interconnected ${ }^{9}$, as neurological modifications affect the behavior patterns in the fish; while changes in behavior affect reproductive system ${ }^{10}$. In this review, we have attempted to discuss the recent scenario of xenobiotic and marine fish interaction and provide a literature overview of biological modifications observed in different marine fish species upon external and internal contact with xenobiotics.

\section{OBSERVATIONS}

\section{Ingestion of marine litters}

Ingestion of litter by different species of marine fish has been reported ${ }^{11,12}$. Approximately 700 species of marine organisms have known to ingest marine litter ${ }^{13}$. Plastics (micro and macro) form the major part $(92 \%)$ of litter ingested by the marine organisms ${ }^{14}$. Plastics are also manufactured as very tiny particles such as micro-beads, plastic nanoparticles, etc. These tiny particles are easily ingested by marine fish impacting the marine food webs, which directly affects the human consumers ${ }^{15}$.

A study ${ }^{16}$ reported information on the presence of marine liter in the stomachs of fish species in diverse marine habitats for the Adriatic and North eastern Ionian macro region. The occurrence of macro litter was studied in 614 specimens belonging to 11 species, on the other hand 230 specimens related to 7 species was studies for micro species. The findings underline the presence of litter in the stomach of the fish Citharus linguatula. The presence of macro litter in the guts was less than $3 \%$ in North eastern Ionian and North Adriatic but approximately in the North Adriatic (Slovenian sea). The ingested micro and macro litter varied depending on the zones. The research concluded that marine fish was affected by macro litter ingestion.

\section{Microplastic ingestion}

Microplastics are ingested by living organisms due to their small size and abundance. Microplastics have been extensively researched for their impact on living organisms including human beings. In marine environment such as ocean and sea microplastics can easily enter the marine organisms due to their very tiny size $(<5 \mathrm{~mm})$. There are several reports which suggest ingestion of these microplastics by marine organisms, fish in precise $\mathrm{e}^{17,18}$. But most of the studies have been reported in the laboratory conditions $^{19}$. A study ${ }^{20}$ in the important fishing zone such as Northwestern African upwelling system has been reported to show the presence of microplastic particles in the digestive tract of Scomber colias (Atlantic chub mackerel). The study revealed out of the gastrointestinal tract examined 120 fish, 78 . $3 \%$ were found have microplastics, $74.2 \%$ showed fibres, $17.5 \%$ had plastic fragments and $16.7 \%$ had 
paint. The study revealed the microplastic contamination in marine fish Scomber colias.

\section{Mercury accumulation}

The release of mercury from anthropogenic and natural sources like incineration and coal combustion reach the aquatic ecosystem by atmospheric deposition ${ }^{21}$ and results in significant repercussions to invertebrates and vertebrates ${ }^{22}$. Mercury is classified into three types of chemicals, elemental, inorganic and organic. Inorganic mercury is the one mostly released to the environment ${ }^{23}$. Many models have been developed to identify the zonal variance of mercury and understand the main culprits ${ }^{24}$. This is the main reason to identify and study the pattern and distribution of mercury in aquatic environment. As the most important source of entry of mercury in humans and animals is the consumption of fish ${ }^{25}$, it is important understand the presence and abundance of mercury in aquatic environment. It also helps to understand the magnitude of mercury pollution reaching the main consumers, human beings ${ }^{26}$. A study ${ }^{27}$ analyzed the total mercury accumulation in the gut and bodies of 13 species of marine fish. They also reported the mercury concentration in water, sediment, fodder materials and fish prey to depict the bio-accumulation dynamics. Marine fish demonstrated high level of mercury accumulation in comparison to fresh water fish. According to the study ${ }^{27}$ mercury content increased in accordance to the trophic level of the consumer. Total mercury levels in marine fish (samples from coastal waters and market) displayed more than the legal limits.

\section{Impact of nano-ZnO on Mugilogobius chulae}

Aquatic toxicity due to nanoparticles has been studied extensively in recent years. However, the studies on the marine fish toxicity and distribution are very limited. A study ${ }^{28}$ reported the impact of zinc oxide nanoparticles on marine fish Mugilogobius chulae. The research team also reported the relative difference in zinc oxide nanoparticles dissolution and dispersal of the same in seawater as well as freshwater. The impact of zinc oxide nanoparticles on hatching, mortality, embryonic development, deformity and histopathology was reported ${ }^{29,30}$. The results indicated that zinc oxide nanoparticles showed higher solubility in seawater than freshwater. The zinc oxide nanoparticles also remarkably inhibited hatching. The $\mathrm{LC}_{50}$ on the fifth day was found to be $45.40 \mathrm{mg} / \mathrm{L}$ with significant spike in the mortality rate. Though exposure to $\mathrm{Zn}^{2+}$ showed hatching inhibition and higher lethality, but its impact was less than the zinc oxide nanoparticles at the similar doses ${ }^{31-33}$. Zinc oxide nanoparticles caused spinal bending, hypoplasia, odema and other deformities in Mugilogobius chulae larvae and embryos. Histopathological studies exhibited hepatocyte and enterocyte enlargement, vacuolar degeneration, and morphological abnormalities of the fish. The study underlines the impact of zinc oxide nanoparticles on marine fish.

\section{CONCLUSION}

The study of the literature on impact of xenobiotics on marine fish shows serious consequences. The entry of different chemicals and their mode of entry are to be given importance by the concerned authorities to avoid more accumulation and distribution. The xenobiotics in marine fish not only impact the aquatic organisms but also human health. So, regulations which govern the presence and release of chemicals are the key to regulate marine pollution due to xenobiotics.

\section{REFERENCES}

1. Wu, J. C., Lai, C. S., Tsai, M. L., Ho, C.T., Wang, Y. J., Pan, M. H. Chemopreventive effect of natural dietary compounds on xenobiotic-induced toxicity. Journal of food and drug analysis, 2017, 25(1), 176-186.

2. Ranjbar, M., Rotondi, M. A., Ardern, C. I., \& Kuk, J. L. Urinary biomarkers of polycyclic aromatic hydrocarbons are associated with cardiometabolic health risk. PLoS One, 2015, 10(9), 0137536.
3. Hu, Hui, Haidong Kan, Gregory D. Kearney, and Xiaohui Xu. "Associations between exposure to polycyclic aromatic hydrocarbons and glucose homeostasis as well as metabolic syndrome in nondiabetic adults." Science of the Total Environment, 2015: 56-64.

4. Xu, C., Li, C. Y.T., \& Kong, A. N. T. Induction of phase I, II and III drug metabolism/ transport by xenobiotics. Archives of pharmacal research, 2005, 28(3), 249.

5. Mandlekar, S., Hong, J. L., \&Tony Kong, A. N. Modulation of metabolic enzymes by dietary phytochemicals: a review of mechanisms underlying beneficial versus unfavorable effects. Current drug metabolism, 2006, 7(6), 661-675.

6. Kamdem, L. K., Meineke, I., Gödtel-Armbrust, U., Brockmöller, J., \&Wojnowski, $\mathrm{L}$. Dominant contribution of P450 3A4 to the hepatic carcinogenic activation of aflatoxin B1. Chemical research in toxicology, 2006, 19(4), 577-586.

7. Mona S. Zaki, Hammam, A. M. and Nagwa S. Ata. Xenobiotics as stressful factors in aquatic system (in fish). Life Sci J, 2014,11(4):188-197

8. Chandra, S., \& Sukumaran, S. Physiological, Biochemical and Neurochemical responses of Cirrhinus mrigala upon short term exposure to Cerium oxide. International Journal of Aquatic Biology, 2020, 7(6), 368-373.

9. Rashmi N, Ranjitha T, Sharath Chandra SP. Chromium and their Derivatives Causes Physiological and Biochemical Modifications in Diverse Fish Models: A Review. 2019. Biomedical and Pharmacology journal, 2019, 12(4): 2049-2053.

10. Ranjitha T \& Sharath Chandra SP. Biological and ecological impact of iron and iron nanoparticles across diverse array of fish models: a review. Ecology, Environment and Conservation, 2020, 26 (1), 180-184

11. Macali, A., Semenov, A., Venuti, V., Crupi, V., D'Amico, F., Rossi, B., Corsi, I., Bergami, E. Episodic records of jellyfish ingestion of plastic items reveal a novel pathway for trophic transference of marine litter. Sci. Rep, 2018, 8, 6105.

12. Kühn S., Bravo Rebolledo E.L., van Franeker J.A. Deleterious Effects of Litter on Marine Life. In: Bergmann M., Gutow L., Klages M. (eds) Marine Anthropogenic Litter. Springer, Cham, 2015.

13. Gall, S.C., Thompson, R.C. The impact of debris on marine life. Mar. Pollut. Bull, 2015, 92, 170-179

14. Phillips, M.B., Bonner, T.H. Occurrence and amount of microplastic ingested by fishes in watersheds of the Gulf of Mexico. Mar. Pollut. Bull, 2015, 100, 264-269.

15. Setälä, O., Fleming-Lehtinen, V., Lehtiniemi, M. Ingestion and transfer of microplastics in the planktonic food web. Environ. Pollut, 2014, 185, 77-83.

16. Anastasopoulou A, Kovač Viršek M, Bojanić Varezić D, et al. Assessment on marine litter ingested by fish in the Adriatic and NE Ionian Sea macro-region (Mediterranean). Mar Pollut Bull, 2018;133:841-851.

17. Ivar Do Sul, J.A., Costa, M.F. The present and future of microplastic pollution in the marine environment. Environ. Pollut, 2014, 185, 352-364.

18. Rezania, S., Park, J., Fadhil, M., Mat, S., Talaiekhozani, A., Kumar, K., Kamyab, H. Microplastics pollution in different aquatic environments and biota: a review of recent studies. Mar. Pollut. Bull, 2018, 133, 191-208.

19. huong, N.N., Zalouk-Vergnoux, A., Poirier, L., Kamari, A., Châtel, A., Mouneyrac, C., Lagarde, F. Is there any consistency between the microplastics found in the field and those used in laboratory experiments? Environ. Pollut, 2016, 211, $111-123$.

20. Herrera, A., Ŝtindlová, A., Martínez, I., Rapp, J., Romero-Kutzner, V., Samper M. D. \& Gómez, M. Microplastic ingestion by Atlantic chub mackerel (Scomber colias) in the Canary Islands coast. Marine pollution bulletin, 2019, 139, 127 135.

21. Krabbenhoft, D.P. Methylmercury contamination of aquatic ecosystems: a widespread problem with many challenges for the chemical sciences. In: Norling, P., Wood-Black, F., Masciangioli, T.M. (Eds.), National Research Council (US) Chemical Sciences Roundtable. Water and Sustainable Development Opportunities for the Chemical Sciences: A Workshop Report to the Chemical Sciences Roundtable. National Academies Press (US), Washington (DC), 2004, pp. 1-13.

22. Wang, F.Y., Outridge, P.M., Feng, X.B., Meng, B., Heimburger-Boavida, L.E., Mason, R.P. How closely do mercury trends in fish and other aquatic wildlife track those in the atmosphere? - implications for evaluating the effectiveness of the Minamata Convention. Sci. Total Environ, 2019, 674, 58-70.

23. Li, Z.W., Huang, M., Luo, N.L., Wen, J.J., Deng, C.X., Yang, R. Spectroscopic study of the effects of dissolved organic matter compositional changes on availability of cadmium in paddy soil under different water management practices. Chemosphere, 2019, 225, 414-423.

24. Houssard, P., Point, D., Tremblay-Boyer, L., Allain, I., Pethybridge, H., Mashou, J., Ferriss, B.E., Baya, P.A., Lagane, C., Menkes, C.E. A model of mercury distribution in tuna from the western and central Pacific ocean: influence of physiology.2019.

25. Kim, K. H., Kabir, E., \& Jahan, S. A. A review on the distribution of $\mathrm{Hg}$ in the environment and its human health impacts. Journal of hazardous materials, 2016, 306, 376-385.

26. Gruszecka-Kosowska, A., Baran, A., Czesława, J. Content and health risk assessment of selected elements in commercially available fish and fish products. Hum. Ecol. Risk Assess. Int. J, 2018, 24 (6), 1623-1641. 
27. Zupo V, Graber G, Kamel S, et al. Mercury accumulation in freshwater and marine fish from the wild and from aquaculture ponds. Environ Pollut, 2019;255:112975

28. Li J, Chen Z, Huang R, Miao Z, Cai L, Du Q. Toxicity assessment and histopathological analysis of nano- $\mathrm{ZnO}$ against marine fish (Mugilogobius chulae) embryos. J Environ Sci (China), 2018;73:78-88.

29. Ates, M., Daniels, J., Arslan, Z., Farah, I.O., Rivera, H.F. Comparative evaluation of impact of $\mathrm{Zn}$ and $\mathrm{ZnO}$ nanoparticles on brine shrimp (Artemia salina) larvae: effects of particle size and solubility on toxicity. Environ. Sci. Processes Impacts, 2013, 15 (1), 225-233.
30. Cong, Y., Jin, F., Wang, J., Mu, J. The embryotoxicity of ZnO nanoparticles to marine medaka, Oryzias melastigma. Aquat. Toxicol, 2017, 185, 11-18.

31. Shih, Y.J., Su, C.C., Chen, C.W., Dong, C.D., Liu, W.S., Huang, C.P. Adsorption characteristics of nano-TiO2 onto zebrafish embryos and its impacts on egg hatching. Chemosphere, 2016, 154, 109-117.

32. Xiong, D., Fang, T., Yu, L., Sima, X., Zhu, W. Effects of nano-scale TiO2, ZnO and their bulk counterparts on zebrafish: acute toxicity, oxidative stress and oxidative damage. Sci. Total Environ, 2011, 409 (8), 1444-1452.

33. Perva, S., Swamy, K., Chandrashekar, N., Subramanian, R., Sukumaran, S., \& Chandra SP, S. Physio-biochemical responses of Indian major carp Catla catla upon sub-chronic exposure to tin oxide nanoparticles. Egyptian Journal of Aquatic Biology and Fisheries, 2020, 24(4), 509-520.

\section{GRAPHICAL ABSTRACT}

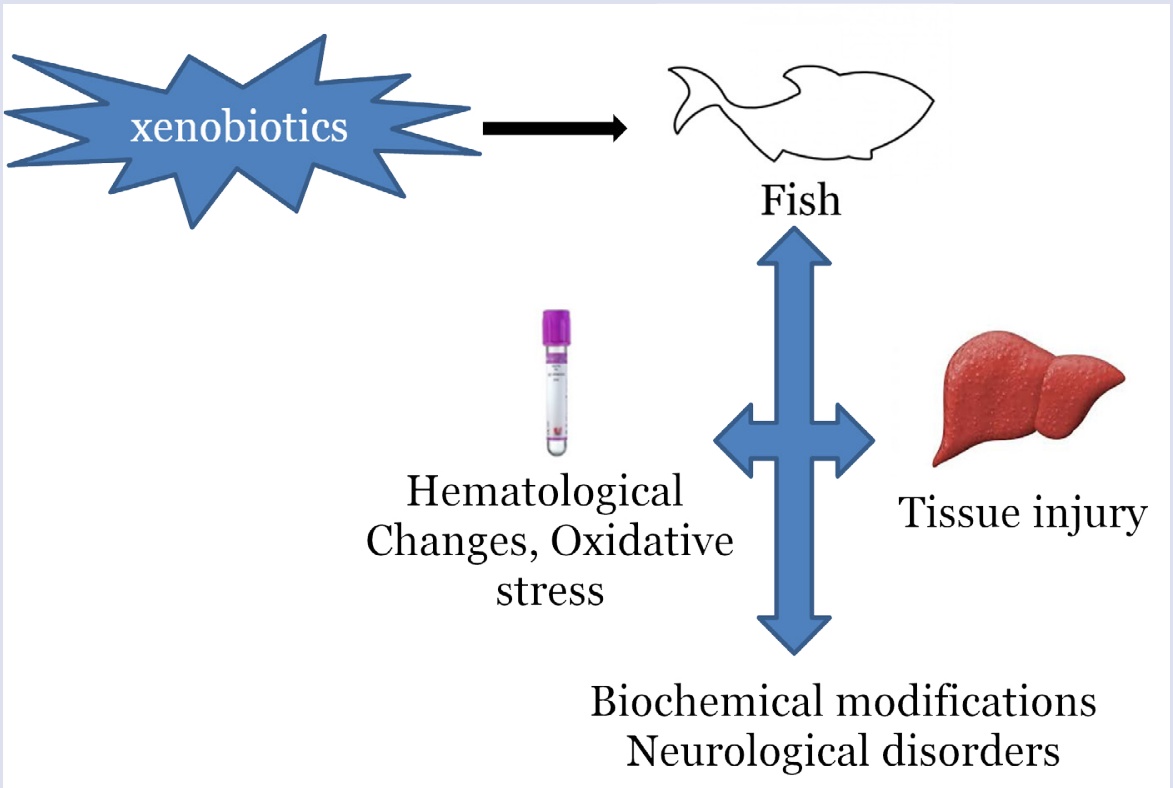

\section{ABOUT AUTHORS}

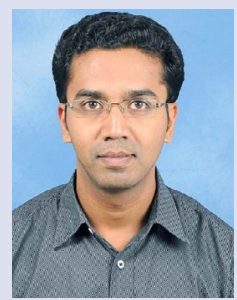

Dr. S. Jagadeep Chandra works as an Assistant Professor in the Department of Microbiology, School of Life Sciences, JSS academy of Higher education and research, Mysuru. He obtained his PhD from University of Mysore in Microbiology. He has served has the Regional director for KSOU previously. His research interests are toxicology and folk medicinal plants.

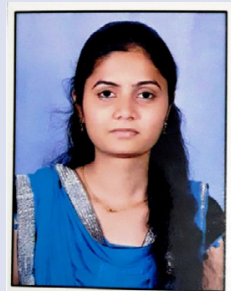

Mrs. Chandana GL works as a tutor in the department of Biochemistry, Hassan Institute of Medical Sciences. She obtained her post-graduation in Medical biochemistry from JSS University, Mysuru.

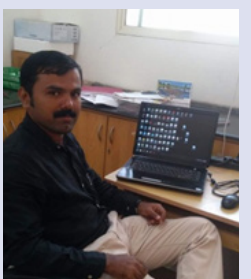

Dr. Naganagouda. V. Kote is an Assistant Professor of Biochemistry in the PG department of studies in Biochemistry, Maharani's Science College for Women, Bengaluru. He has more than 10 years of teaching and research experience. He has served as the Principal investigator for project funded by UGC. Dr. Gouda is a Gold Medalist in M.Sc Biochemistry. He has to his credit several publications in International peer reviewed journals. 
Dr. Sharath Chandra SP is an Assistant Professor of Biochemistry in Government Science College, Hassan, India. He has more than 12 years of research experience with publications in peer reviewed International journals. He is recipient of International young scientist awards from International science associations like FAOBMB, ISN.

Cite this article: Jagadeep CS, Chandana GL, Kote NV, Sharath CSP. Recent Scenario of Impact of Xenobiotics on Marine Fish: An Overview. Pharmacogn J. 2020;12(6)Suppl:1797-800. 